\title{
Metamorfoses do mundo do trabalho e o dano existencial: o direito à desconexão do trabalho
}

\author{
Metamorphosis in world of work and the \\ existential damage: the right to be disconnect \\ from work
}

\section{Alexandre Antonio Bruno da Silva ${ }^{1}$ Marlea Nobre da Costa Maciel ${ }^{2}$}

\begin{abstract}
Resumo: $\mathrm{O}$ artigo trata do dano existencial ao trabalhador provocado pelo meio ambiente do trabalho. O personagem kafkiano Gregório Samsa representa o trabalhador comum que, mesmo metamorfoseado, preocupa-se mais com o seu trabalho do que com a sua condição. As transformações do mundo do trabalho globalizado fragilizaram a vida e a identidade do trabalhador. As crescentes exigências laborais, as
\end{abstract}

1 Doutor em Direito pela PUC-SP. Doutorando em Políticas Públicas pela UECE. Mestre em Direito pela UFC. Mestre em Informática pela PUC-RJ. Professor do Programa de Mestrado em Direito do Centro Universitário Christus (UNICHRISTUS). Professor Adjunto da Universidade Estadual do Ceará (UECE). Auditor-Fiscal do Trabalho.E-mail: alexandre_bruno@terra. com.br.

2 Mestranda em Processo e Direito ao Desenvolvimento (UNICHRISTUS). Especialista em Trabalho e Processo do Trabalho (UNICHRISTUS). Graduada em Direito pela Universidade de Fortaleza. Advogada. E-mail: marleanobre@ hotmail.com. 
novas tecnologias, o aumento da produção e o trabalho repetitivo impossibilitam a desconexão do trabalhador. É necessário um meio ambiente do trabalho socialmente sustentável, onde o trabalhador goze do ócio criativo para a sua autodeterminação. No estudo, utilizou-se pesquisa bibliográfica por meio de livros, artigos, normas nacionais que ilustram a presença do tema no contexto brasileiro. Os julgados dos tribunais, em sua maioria, consideraram o direito à desconexão como fundamental para o trabalhador. O diálogo com a obra de Kafka e Chaplin ressignifica o trabalhador, colocando-o em evidência. A vida e o trabalho podem ser objeto de reflexões e de escolhas. O labor não precisa ser sinônimo de alienação, sustento e exploração. O diagnóstico e a quantificação do reparo ao dano existencial carecem de estudo mais aprofundado.

Palavras-chave: Dano existencial; Direito à desconexão; Kafka; Mundo do Trabalho; Metamorfose.

Abstract: This paper deals with the existential damage to workers caused by the working environment. The Kafkaesque character Gregório Samsa represents the ordinary worker who, even though metamorphosed, worries more about his work than about his condition. The transformations in the world of work in an era of globalization and fast technological changes caused insecurity to the life and to the identity of the workers. Increasing labor demands, the new technologies, increased production and the repetitive work make impossible for workers be disconnected. A socially sustainable working environment is needed, where the worker enjoys creative leisure for his selfdetermination. In the study, we used bibliographical research through books, articles, and Brazilian legal norms that illustrate the presence of the theme in the Brazilian context. Most of court judges considered the 
right of disconnection fundamental to workers. The dialogue with the work of Kafka and Chaplin gives a new signification to worker, puts it in evidence. Life and work must be the object of reflection and choice. Labor does not have to be synonymous with alienation, sustenance and exploitation. The correct diagnostic and repair of existential damage needs further study.

Keywords: Existential damage; Right to be disconnect; Kafka; World of work; Metamorphose.

\section{INTRODUÇÃO}

O mundo do trabalho tem passado por uma série de transformações que aprofundam a sempre presente indeterminação do futuro. A globalização e as novas formas de produção exigem do trabalhador constante adaptação. Em meio ao turbilhão de mudanças, trabalhadores são levados ao bel prazer dessas metamorfoses.

O movimento frenético os atinge em cheio, jogados de um lado para o outro, muitas vezes uns contra os outros, buscam o quase impossível equilíbrio. Nesse processo, difícil saírem ilesos. Sofrem metamorfoses que, muitas vezes, provocam não apenas um episódico desequilíbrio em suas vidas, mas uma completa transformação, levando para longe os seus sonhos e projetos de vida.

O presente texto não se limita a explicitar as alterações vividas pelo trabalhador e seu contexto laboral. Visa-se provocar uma discussão mais aprofundada sobre o tema. Neste desiderato, inicialmente trata da metamorfose sofrida pelo trabalhador moderno, muito bem representada nas obras de Franz Kafka e Charles Chaplin.

Fugindo um pouco do lugar comum de exploração do trabalhador pelo tomador de sua força de trabalho, apresen- 
ta-se a auto exploração do trabalhador, igualmente danosa, provocada pelos desejos e necessidades, sempre presentes, na sociedade de consumo. $\mathrm{O}$ medo de perder o emprego, que inviabiliza a sobrevivência, ganha um reforço: o medo de perder a condição de consumidor.

A metamorfose humana é o mote desse estudo, mas sob a ótica do ambiente do trabalho, que exige a presença, a atenção, a produção e a vida do empregado. Exigências contínuas são feitas ao trabalhador. A tecnologia que oferecia como grande promessa um menor desgaste humano, transforma-se em seu maior peso. Não há possiblidade de desconexão mental e física, não há como fugir. O trabalho acompanha o trabalhador por pensamentos, palavras, atos e omissões. É esta impossibilidade de desconexão que fundamenta o estudo desta espécie de dano.

Quando o trabalhador está sempre à disposição, em sobreaviso ou alerta às demandas do labor, a preservação da sua integridade física e mental encontra-se em risco, pois deixa de dedicar-se com gosto aos momentos de lazer e de convivência com a família e amigos.

É importante o momento de ócio, é preciso haver um tempo para que se promova uma atitude mental contemplativa. O lazer não deve ser jamais confundido com o castigo cruel do desemprego. É preciso investir em si mesmo, ser criativo, ressignificar seu conhecimento ou até mesmo optar por outro trabalho, ou, quem sabe, seguir um outro caminho.

O tema é de grande relevância no direito do trabalho. $\mathrm{O}$ avanço da tecnologia que ocorreu através das redes de computadores, smartphones e diversos outros sistemas criados permitem que o trabalhador possa ter mais conforto em suas atividades. Entretanto, ao mesmo tempo, essa mesma tecnologia permite que as jornadas de trabalho se estendam por várias horas. $\mathrm{O}$ trabalho pode ser executado dentro da 
casa do próprio trabalhador, deixando-o constantemente de sobreaviso.

A Lei 13.467, de 13 de julho de $2017^{3}$, alterou o texto da Consolidação das Leis do Trabalho, regulando a possibilidade do reconhecimento e reparação do dano existencial no direito do trabalho brasileiro. Entretanto, há muito o que ser discutido sobre o tema. Ao mesmo tempo que reconheceu o dano existencial, a reforma trabalhista criou uma tabela que limita os valores referentes às indenizações possíveis, categorizadas segundo o grau de ofensa.

É necessário compreender mais profundamente o bem atingido no caso do dano existencial. A mera previsão legal pode tornar mecânico o seu reconhecimento e reparação, o que pode se mostrar prejudicial em relação ao bem protegido. Além disso, como é baseado em critérios de difícil objetivação, a jurisprudência tem tomado decisões bastante díspares, por exemplo, ao discutir sobre a necessidade ou não da prova do dano.

No presente trabalho, utilizou-se pesquisa bibliográfica por meio de livros, artigos, normas nacionais e internacionais que ilustram a importância do tema no contexto brasileiro e internacional. No Brasil, os julgados dos tribunais, em sua maioria, consideraram o direito à desconexão como fundamental para o trabalhador. Entretanto, verifica-se que o diagnóstico e a quantificação do reparo ao dano existencial carecem de um estudo mais aprofundado.

3 BRASIL, 2017. 


\section{AS METAMORFOSES NO MUNDO DO TRA- BALHO: O MEDO DO DESEMPREGO E A PRECARIZAÇÃO}

Franz Kafka, em sua obra "Metamorfose", narra o epílogo da vida de Gregório Samsa, que certo dia acorda de seus sonhos intranquilos e encontra-se em sua cama metamorfoseado em um monstruoso inseto. Descobre-se deitado sobre as suas costas duras como couraça. Levanta um pouco a sua cabeça, vê seu ventre abaulado, marrom, dividido por nervuras arqueadas. Suas numerosas pernas, lastimavelmente finas em comparação com o volume do resto do corpo, tremulavam desamparadas diante dos seus olhos. ${ }^{4}$

Gregório Samsa, até então, era um trabalhador comum, insatisfeito e infeliz com a vida que levava, não via o momento de se "libertar". Entretanto, ao acordar, toda a sua angustia havia tomado corpo, o seu próprio corpo. Sua carapaça dura ao mesmo tempo que o permitiria suportar os seus desafios diários, representa o peso de sua existência. As suas possibilidades de superação estavam entregues ao que lhe parecia mais debilitado, suas frágeis pernas.

Traço marcante do início desta obra é a necessidade que o personagem tem de trabalhar para o seu sustento e o de sua família. Curiosamente, ao invés de se preocupar com a sua situação ou com o que havia lhe acontecido passa a pensar no trabalho. Mesmo após perceber que a sua nova condição era real, o trabalho era o que mais o angustiava. Como iria se deslocar? Como iria trabalhar daquela maneira? Estaria o seu emprego correndo perigo? O que iria explicar para o patrão? Estaria o sustento de sua família em risco?

$4 \quad$ KAFKA, 1997, p.7. 
Os seus pensamentos não se desligavam do seu trabalho. Preocupava-se com o relógio de ponto. Pensava nos problemas que a sua ausência ou o seu atraso poderiam ocasionar para si na empresa. Lembrava das diversas obrigações que tinha a cumprir. O trabalho constitui-se em algo mais relevante do que a transformação que acontecera em sua vida. Essa é a preocupação de grande parcela dos trabalhadores, para quem o trabalho é sinônimo de sustento e possibilidade de consumo. O desemprego acarreta perda da autonomia, da autoconfiança e da saúde física e psicológica. ${ }^{5}$

O trabalho representa o meio para o consumo, não sendo raros os casos onde o trabalhador torna-se vítima de seus desejos e necessidades. A ausência de trabalho ocasiona o afastamento da condição de consumidor e a consequente exclusão social. ${ }^{6}$ Trabalhar, cumprir prazos, chegar no horário, estar disponível, ficar de sobreaviso, instabilidade, substituibilidade não são características apenas do operariado das primeiras revoluções industriais. Representa a fatia mais importante da vida da grande massa de trabalhadores no Brasil e no mundo.

Essa massa de trabalhadores, ou, como denominado por Ricardo Antunes ${ }^{7}$, massa de subproletariados, segue executando o seu labor muitas vezes de forma parcial, precária, temporária ou subcontratada. Cada subproletário busca, acima de tudo, manter-se ocupado. Reinventa-se para não ser excluído e, para isso, por vezes, também põe em risco a própria existência.

O subproletariado de que vamos falar é aquele que habita as zonas periurbanas. Não se trata aqui de uma classe social no sentido que os homens políticos italianos, por exemplo, entendem.

\footnotetext{
5 SEN, 2010, p.36-37.

6 BAUMAN, 2005, p. 22-23.

7 ANTUNES, 2015, p. 65.
} 
Mas da fração da população que ocupa as favelas ou os cortiços, geralmente jogados na periferia das grandes cidades. Esta população não se caracteriza pela participação comum em uma mesma tarefa industrial. Ao contrário, o que a une é mais o não-trabalho e o subemprego. ${ }^{8}$

A forma de produção, ao longo do tempo, também passou por diversas metamorfoses. A globalização força uma constante reestruturação e reconstrução das forças produtivas, que boa parte das vezes resulta na expansão das diversas formas de precarização do trabalho. ${ }^{9}$ Ao mesmo tempo, define-se um novo modelo de sociedade em que se valoriza o consumo de bens, as falsas necessidades e a fragilização dos sentimentos e dos valores. ${ }^{10}$

Não há espaço para todos. ${ }^{11} \mathrm{O}$ capital humano qualifica-se, mas vislumbra no mercado poucas perspectivas de emprego. ${ }^{12}$ As pessoas que seguem empregadas, ouvem que é necessário um compromisso com a missão da empresa, serem felizes e fiéis, mesmo que tenham que ocupar funções aquém de suas qualificações ou com oferta de salários cada vez mais baixa. ${ }^{13}$ É essencial não ser excluído da rede.

A preocupação com a não exclusão e de não ser considerado desnecessário permeia o cotidiano dos trabalhadores. De acordo com Manuel Castells, a tecnologia não destruiu o emprego, mas alguns tiveram que ser substituídos por outros. Houve um aumento de exigência das habilidades e do nível de estudo, porém, com a globalização, milhares de empregos foram eliminados, seja porque deixaram de existir,

\footnotetext{
8 DEJOURS, 1987, p.27.

9 BLASS, 2007, p. 26.

10 MARCHESINI, 2012, p. 132.

11 BAUMAN, 2005, p. 24.

12 STANDING, 2017, p. 109.

13 STANDING, 2017, p. 119.
} 
seja por causa dos deslocamentos da procura pela mão de obra em países recém-industrializados. ${ }^{14}$

Desta forma, o trabalhador que convive com o receio diário de ser excluído não consegue desconectar do seu trabalho, não percebe o quanto está se "desumanizando". Trabalhadores, por vezes, parecem uma massa de viciados em drogas ilícitas exibidos no seriado da TV, "Drugs, Inc". ${ }^{15}$ A vida deste se resume a trabalhar (pedir esmolas nos semáforos e na diuturna distribuição de pequenas quantidades de drogas que serão consumidas por outros viciados), consumir algo, comer e em último caso, descansar.

A existência e seus projetos de vida são deixados para trás. Os pequenos prazeres, a luta pela subsistência e o medo de perdê-la ocupam todos os pensamentos. Neste momento, parece importante repetir o texto escrito pelo estudante francês Richard Deshayed, momentos antes de ter sua vida ceifada por uma granada, "viver não é sobreviver". ${ }^{16}$ Viver está muito além do simples sobreviver: um ser "doente" sobrevive, aquele que abraça a vida, vive.

O personagem kafkiano, em função da sua sobrevivência e da de sua família, vivia sua condição de vida exercendo uma atividade que não o agradava, a ponto de fazê-lo esquecer de quem era. Muitos trabalhadores, da mesma forma, seguem a sua marcha diária em função do trabalho que se sobrepõe ao ser.

Carlitos, personagem de Charles Chaplin no filme Tempos Modernos, da mesma forma, passa por uma metamorfose. ${ }^{17}$ Ele representa o trabalhador que perde o controle do ritmo do seu próprio trabalho, que passa a ser dado pela

14 CASTELLS,2016, p. 11.

15 NGS, 2010.

16 DELEUZE, 1985 , p. 56-57.

17 CHAPLIN, 1936. 
esteira de produção. Além disso, verifica-se na representação, a divisão das atividades que passa a ser comum no mundo do trabalho e que termina por transformar a vida das pessoas e a forma de ver problemas complexos. Após longo período de trabalho em uma fábrica, executando movimentos repetitivos, o personagem mantém-se preso a automação mesmo após o seu horário de trabalho. Continua no seu ritmo frenético, segue a sua vida, indiferente aos outros e a si mesmo.

As constantes alterações na economia, nas dinâmicas do mercado e nas clivagens da tecnologia fizeram com que a temática da metamorfose do mundo do trabalho assumisse grande importância. O impacto social exige o redirecionamento das políticas governamentais voltadas para a geração de emprego e renda. Hannah Arendt analisando a era moderna aponta uma preocupação acerca da "[...] perspectiva de uma sociedade de trabalhadores sem trabalho [...]". Da necessidade de se pensar o que se está fazendo com a sociedade, com a humanidade e com a sua condição. ${ }^{18}$

Se não me contivesse, por causa dos meus pais, teria pedido demissão há muito tempo; teria me postado diante do chefe e dito o que penso do fundo do coração. Ele iria cair da sua banca! Também, é estranho o modo como toma assento nela e fala de cima para baixo com o funcionário - que além do mais precisa se aproximar bastante por causa da surdez do chefe. Bem, ainda não renunciei por completo à esperança: assim que juntar o dinheiro para lhe pagar a dívida dos meus pais - deve demorar ainda de cinco a seis anos - vou fazer isso sem falta. Chegará então a vez da grande ruptura. Por enquanto, porém, tenho de me levantar, pois meu trem parte às cinco. ${ }^{19}$

Pode-se dizer que há um pouco de Gregório Samsa em cada trabalhador, ante a possibilidade do desemprego

18 ARENDT, 2014, p. 6.

19 KAFKA, 1997, p.9. 
e o medo de não se enquadrar nas necessidades do mercado globalizado. Não há espaço para insatisfação, para conjecturas ou indagações; a angustia perene é a de se estar trabalhando. A preocupação com o presente e com o futuro próximo, apaga qualquer linha do horizonte. Do mundo dos sonhos, a esperança resume-se a um dia pagar suas dívidas e, quem sabe, tornar-se livre. Até que um dia há, apenas, o "nada mais além". ${ }^{20}$

Pedro não sabe mas talvez no fundo espere alguma coisa mais linda que o mundo.

Maior do que o mar, mas prá que sonhar se dá o desespero de esperar demais.

Pedro pedreiro quer voltar atrás, quer ser pedreiro pobre e nada mais, sem ficar....

Esperando, esperando, esperando, esperando o sol.

Esperando o trem, esperando aumento para o mês que vem Esperando um filho prá esperar também.

Esperando a festa, esperando a sorte, esperando a morte, esperando o Norte.

Esperando o dia de esperar ninguém, esperando enfim, nada mais além. ${ }^{21}$

A vinculação ao trabalho e manter-se nessa condição de empregado, mesmo que seja em algo que não agrade, é mais importante do que a própria percepção de si mesmo. O que vale, é manter-se (aparentemente) seguro e estável nessa relação, durante o maior tempo possível. Não importa se há fatores externos que podem influenciar na obtenção ou manutenção do emprego. A sociedade considera que o Ser é autor do seu próprio destino, responsável por suas escolhas e cobra isso. ${ }^{22}$

20 HOLLANDA, 1966.

21 HOLLANDA, 1966.

22 BAUMAN, 2010, p. 34. 
Bauman dialogando com Donskis afirma que há uma ansiedade ante as incertezas da vida em uma sociedade individualizada como a atual. ${ }^{23}$ Quase sempre estão presentes a instabilidade no emprego, a flexibilidade do mercado de trabalho, a possibilidade de redução do orçamento familiar, as dívidas que se seguem, a preocupação com a velhice e a fragilidade dos vínculos. Condições de incerteza que, se prolongadas, provocam sensações humilhantes: a ignorância de não saber o que o futuro trará e a impotência de ser incapaz de influenciar em seu curso.

Todas essas incertezas refletem na vida do trabalhador, na manutenção de um trabalho extenuante e alienante, ou no receio de ficar desempregado. Há que se verificar que possibilidade de desemprego é essa? Houve uma alteração qualitativa na forma de ser do trabalho? Ricardo Antunes aponta que houve tanto impulsionamento para uma maior qualificação do trabalho como para uma maior desqualificação. ${ }^{24}$

Os de maior qualificação representam a "intelectualização do trabalho manual", formada por profissionais superqualificados. Os mais desqualificados geralmente são aqueles que formam a massa de trabalhadores temporários, parciais (intermitentes), subcontratados, chamados de "subproletariado moderno" ${ }^{25}$ Cada um cumpre o seu papel no mundo do trabalho. Guy Standing assevera que o trabalho precisa ser "resgatado" diferenciado do emprego e da tarefa. ${ }^{26}$ Para ele, todas as formas de trabalho deveriam ser tratadas com igual respeito - mesmo as flexibilizadas, terceirizadas ou temporárias.

23 BAUMAN; DONSKIS, 2014, p. 122.

24 ANTUNES, 2015, p. 73.

25 ANTUNES, 2015, p. 73.

26 STANDING, 2017, p. 241. 
Hannah Arendt aponta que a distinção entre trabalho qualificado e trabalho não qualificado perde certa importância quando se observa o resultado. ${ }^{27} \mathrm{O}$ que se negocia no mercado de trabalho não é a qualificação de cada trabalhador, mas a força de trabalho e a sua quantidade. ${ }^{28}$ Essa força de trabalho, qualificada ou não, segue conectada ao "relógio de ponto" do mercado globalizado que exige cada vez mais produção e resultado. A competitividade do mercado dá o tom e a produção - seja pela força de trabalho intelectual, seja braçal - é a sua energia. Guy Standing afirma que:

[...] o mercado global é uma máquina que funciona no esquema 24/7; nunca dorme ou relaxa; não tem nenhum respeito pela luz do dia ou escuridão, pela noite e pelo dia. [...] se um país, empresa ou indivíduo não se adapta à cultura do tempo $24 / 7$, haverá um preço a pagar. [...]. ${ }^{29}$

As metamorfoses no mundo do trabalho, mesmo que resultem na exigência da alteração do tipo de mão de obra, ao final, está mesmo é interessada na capacidade de produção (intelectual ou manual) daquela força de trabalho. O resultado dessa produção é o que o mercado espera e põem em circulação. Não se amoldando a esse ritmo, paga-se o preço com o desemprego e exclusão. $\mathrm{O}$ trabalhador qualificado ou com baixa (ou sem) qualificação experimenta diuturnamente a sensação da incerteza. ${ }^{30}$ Há insegurança acerca da durabilidade do emprego, questiona-se quando (e se) vai ficar desempregado.

O fim do emprego "estável" paira o meio ambiente do trabalho contemporâneo, dando azo a figura do "trabalhador hifenizado", caracterizado por se inserir no mercado

27 ARENDT, 2014, p. 111

28 ARENDT, 2014, p. 111.

29 STANDING, 2017, p. 178.

30 BLASS, 2007, p. 27. 
de trabalho através de um "contrato não-padronizado de trabalho" ${ }^{31} \mathrm{O}$ trabalhador-hifenizado executa suas funções em trabalhos de meio expediente, temporário, ocasional, por conta própria, franqueados ou domésticos, mostrando-se como trajetória da vida de muitos profissionais. ${ }^{32}$ Nestes casos, o importante é estar contratado, mesmo que de forma precária.

Entende-se que trabalho e emprego são significativos e necessários, mas não podem ser confundidos com a essência da vida do homem. Bertrand Russell diz que a simples ideia de que os pobres deveriam ter direito ao lazer chocou e incomodou aos ricos. Afinal, o que querem os pobres com feriados? O que irão fazer com tanto lazer? Pobres devem estar trabalhando. ${ }^{33}$

O tempo livre e o ócio também devem fazer parte da vida do trabalhador, inclusive como elementos que se somam ao processo criativo. Não é aceitável que a sociedade e o mercado sigam num ritmo de dominação a ponto de destruir a própria humanidade. Vive-se em busca de um consumo alienante e o trabalho acaba por ser um reflexo disso. O trabalhador é ao mesmo tempo vítima e algoz desse sistema. Ao mesmo tempo em que segue num labor que não permite sua desconexão, também busca ocupar-se mais e mais a fim de ter mais recursos para aumentar o seu consumo. Consome-se para consumir.

Vivemos uma fase histórica particular em que a própria liberdade dá lugar a coações. A liberdade do poder fazer engendra até mais coações do que o dever disciplinar. O dever tem um limite. O poder fazer, pelo contrário, não tem limite algum. É por isso que a coação que provêm do poder fazer é ilimitada. [..] A liberdade, que deveria ser o contrário da coação, engendra coações. Patologias como a

31 BEYNON, 1995, p. 5-27.

32 BLASS, 2007, p. 27.

33 RUSSELL, 2002, p. 29-30. 
depressão e a síndrome de burnout são a expressão de uma crise profunda da liberdade. ${ }^{34}$

Mészáros afirma que há uma crueldade nessa dominação. Faz-se necessária uma emancipação humana, principalmente quanto à forma como se reproduz as condições materiais de vida nas horas dedicadas ao trabalho, quando comparadas às horas dedicadas a outras atividades. Entretanto, acredita que essa mudança só poderá ocorrer por meio de uma transformação na "ordem sociometabólica". É preciso alterar-se o vigente metabolismo social do capital em um compromisso com a humanidade. Porém, lembra que o capital somente irá interessar-se pela redução do tempo de trabalho se estiver a serviço da acumulação de capital e da maximização do lucro. ${ }^{35}$

Desta forma, o mercado segue seu natural curso em busca do lucro e arredio ao tempo livre. A sensação de insegurança submete o trabalhador a uma conexão permanente com o seu trabalho ou com o medo do desemprego. A sensação de incerteza gera danos existenciais além dos biológicos (danos à saúde). Guy Standing aponta que:

Devemos encontrar maneiras de permitir que todos nós tenhamos mais tempo para o trabalho que não é tarefa e para o ócio que não é diversão. Se não insistirmos em um conceito mais rico de trabalho, continuaremos a ser levados pela insensatez de medir o valor de uma pessoa pelo emprego que ela tem [...]. ${ }^{36}$

Leila Blass cogita se seria possível imaginar uma vida social em que as pessoas se reconheçam e sejam reconhecidas por seu saber fazer. ${ }^{37}$ Mas, para isso, há que ter um momen-

\footnotetext{
34 HAN, 2015, p. 11-12.

35 MÉSZÁROS, 2015.

36 STANDING, 2017, p. 41.

37 BLASS, 2007, p. 25-37.
} 
to em que a mente do trabalhador esteja livre para outras experiências. Restaria também, como desejo (utópico), um momento para se desconectar e para decidir o que fazer com o tempo livre. E arremata:

[...] Nesse caso, a obtenção de rendimentos dependeria da venda dos produtos fabricados por suas mãos que exigem um conjunto de conhecimentos para execução de uma tarefa, muitas vezes, adquiridos ao longo da vida e através das gerações. Assim, a liberdade no uso do tempo e a autonomia na escolha do que fazer e como fazer poderia ser preservado. [...]. ${ }^{38}$

Assim, mesmo que as oportunidades de emprego estejam se transformando, adaptando-se às exigências do mercado globalizado, a "venda" da força de trabalho (mesmo que precária) ainda se mantém dentro das necessidades daqueles que desejam manter-se na rede. ${ }^{39} \mathrm{O}$ mercado necessita da mão de obra ao mesmo tempo produtora e consumidora. A sociedade de consumo espera das pessoas o exercício de sua dupla função. Ao mesmo tempo que é um elemento da produção (um insumo) é consumidor do que é posto em circulação (bens ou serviços).

As exigências do mercado por vezes demandam uma flexibilização das relações laborais. Caso o trabalhador esteja irremediavelmente conectado ao seu trabalho sofrerá um crescente processo de "desintegração". É preciso que se tenha em mente que ter ou não um emprego não pode ser o elemento caracterizador da identidade das pessoas, sob pena de viverem sob estresse e temerem perder o seu valor social. A personagem kafkiana representa bem esse trabalhador que não percebe que sua existência se esvaia, pois para ele a "[...] A condição humana do trabalho é a própria vida". ${ }^{40}$

38 BLASS, 2007, p. 35.

39 CASTELLS, 2016, p. 12.

40 ARENDT, 2014, p. 8. 
Domenico de Masi ${ }^{41}$ é outro autor que ressalta a importância do ócio, fazendo uma analogia com a obra "The Unbound Prometheus" (Prometeu Desacorrentado) de David S. Landes ${ }^{42}$, que versa sobre o nascimento da sociedade industrial. Nele, graças às máquinas, o homem tem os seus membros desacorrentados, agora exige essa mesma liberdade para o cérebro, para a alma. Liberdade do ócio para criação. ${ }^{43}$

Cláudio da Rocha (2018, p. 17) sobre a relação homem e trabalho, aponta que a conduta humana do trabalho é uma atividade paradoxal, podendo ser, simultaneamente, fonte de sensações boas e ruins; pode ser fonte de subsistência e, ao mesmo tempo, corresponder à venda da liberdade; trazer uma alegria ou ser a lágrima que escorre do rosto do trabalhador; pode ser autorrealização, mas também alienação.

Karl Marx ao tratar sobre a alienação e o estranhamento do trabalho (do trabalhador) aponta que o trabalhador se torna uma mercadoria à medida que seu trabalho se fixa ao objeto produzido, vai se desefetivando, se objetivando a ponto de desaparecer:

[...] O trabalhador se torna uma mercadoria tão mais barata quanto mais mercadorias cria. Com a valorização do mundo das coisas (Sachenwelt) aumenta em proporção direta a desvalorização do mundo dos homens (Menschenelt). O trabalho não produz somente mercadorias; ele produz a si mesmo e ao trabalhador como uma mercadoria [...] O produto do trabalho é o trabalho que se fixou num objeto, [...].

41 MASI, 2000, p. 15.

42 LANDES, 1988.

43 Domenico De Masi fala do ócio criativo, aquele tempo preenchido com ações escolhidas por vontade própria, desprendidas dos condicionantes do trabalho. "É a situação do poeta, do cientista, do estudante, do amante de xadrez [...] A criatividade se nutre de desperdício: de milhares de horas de reflexão ou exercício [...] uma perambulação da mente, que mais cedo ou mais tarde acaba desembocando numa ação positiva: numa obra de arte, num teorema, num romance". (MASI, 2000, p. 247). 
$\mathrm{Na}$ determinação de que o trabalho se relaciona com o produto de seu trabalho como [com] um objeto estranho estão todas estas consequências. Com efeito, segundo esse pressuposto está claro: quanto mais o trabalhador se desgasta trabalhando (ausarbeitet), tanto mais poderoso se torna o mundo objetivo, alheio (fremd) que ele cria diante de si, tanto mais pobre se torna ele mesmo, seu mundo interior, [e] tanto menos [o trabalhador] pertence a si próprio. ${ }^{44}$

A alienação tem no trabalho o seu ventre materno, trata-se da exploração do homem (força de trabalho) pelo homem (explorador da força de trabalho) e para o homem (consumidor). Trabalho que mantém o trabalhador alienado de si mesmo e da realidade. ${ }^{45} \mathrm{O}$ homem atua, mesmo sem o saber, nas diversas fases deste processo, que é cíclico. A produção (força de trabalho), o consumidor e o lucro são os principais interesses do mercado.

\section{O DIREITO A DESCONEXÃO E A IMPORTÂN- CIA DO ÓCIO: A "EXISTÊNCIA" DO TRABA- LHADOR E O MEIO AMBIENTE LABORAL}

Gregório e Carlitos mostram-se conectados ao trabalho e desconectados de sua própria existência. Como em tantos outros casos, ocorre um dano a existência do trabalhador. Dano que tomou conta do ser, absorveu-o em um processo de fagocitose: a essência do trabalhador foi "digerida" pelo seu trabalho. O dano extrapatrimonial não cabe mais dentro do conceito de dano moral, vai além, torna-se um dano existencial.

Júlio César Bebber, conceituando dano existencial, afirma que este é um dano ao projeto de vida da pessoa e se

44 MARX, 2008, p. 81.

45 BARROS, 2011, p. 229. 
apresenta como uma lesão capaz de pôr em risco a liberdade de escolha e o destino elaborado. ${ }^{46}$ Frustra seus desejos de vida para o futuro, seus sonhos e anseios, provocando um vazio existencial e obrigando a pessoa a resignar-se, tal como o lamento vivido por Gregório Samsa, que colocava o trabalho (e o medo de perdê-lo) como a preocupação mais importante de sua vida.

A preocupação com os danos que a ausência do tempo livre, mediante jornadas exaustivas ou labor em sobreaviso, pode causar ao trabalhad or foram objeto de estudo no direito italiano e este se estendeu ao direito brasileiro, tendo sido sua reparabilidade inicialmente fundamenta nos artigos $1^{\circ}$, III e $5^{\circ}$, V e X da Constituição Federal de 1988. ${ }^{47}$

Especificamente no direito trabalhista, a Lei 13.467, de 13 de julho de $2017^{48}$ incluiu na Consolidação da Leis do Trabalho (CLT) ${ }^{49}$ o art. 223-A e seguintes que tratam da reparação de danos de natureza extrapatrimonial decorrentes da relação do trabalho. Neste sentido, o art. 223-B define como causadora de dano de natureza extrapatrimonial a ação ou omissão que ofenda a esfera existencial da pessoa.

A ausência do tempo libero, como é chamado pelos italianos, destinado ao trabalhador, foi apreciado pela Suprema Corte italiana pela primeira vez no ano 2000. Neste julgado, a corte proferiu decisão reconhecendo o dano existencial provocado pela ausência do trabalhador nas suas atividades de vida diária, social e afetiva, que teriam atingido a sua dignidade. Seria um dano ao projeto de vida e um dano ao convívio social e familiar.

\footnotetext{
46 BEBBER, 2009, p.28.

47 BRASIL, 1988.

48 BRASIL, 2017.

49 BRASIL, 1943.
} 
O dano existencial, ou seja, o dano à existência da pessoa, portanto, consiste na violação de qualquer um dos direitos fundamentais da pessoa, tutelados pela Constituição Federal, que causa uma alteração danosa no modo de ser do indivíduo ou nas atividades por ele executadas com vistas ao projeto de vida pessoal, prescindindo de qualquer repercussão financeira ou econômica que do fato da lesão possa decorrer..$^{50}$

Inicialmente, a doutrina italiana definiu o dano à vida de relação (danno alla vita di relazione), uma espécie de dano ao relacionamento social, concebido de acordo com as atividades sociais. Tratava-se de uma ofensa física ou psíquica que impedia a pessoa de desfrutar os prazeres propiciados por atividades recreativas, sociais e esportivas que repercutiam no seu estado de ânimo. Nota-se, no caso, a preponderância do elemento psicológico, em que as atividades sociais adquirem um profundo valor, em função de sentimentos do indivíduo. ${ }^{51}$

Anteriormente, a sentença 184 de 1986, da Corte constitucional italiana, combinou o disposto nos arts. 2.043 do Código Civil italiano e $2{ }^{\circ}$ da Constituição da República italiana, definindo o dano biológico ou dano à saúde (danno biologico, danno alla salute). ${ }^{52}$ A plicável, pela abrangência dos seus enunciados, a qualquer lesão análoga de direitos igualmente fundamentais da pessoa, configurando dano. ${ }^{53}$ Trata-se de dano indenizável independentemente de um prejuízo patrimonial e de que o dano, como exige a lei italiana, seja decorrente de um ilícito penal. ${ }^{54}$

50 ALMEIDA NETO, 2005.

51 COUTO E SILVA, 1997, p. 217-34.

52 UT, 2018.

53 ALMEIDA NETO, 2005 p. 28-29.

54 COUTO E SILVA, 1997, p. 217-34. 
As sentenças 500/99 e 7.713/ 2000, da Corte de Cassação Italiana introduziram a noção de dano existencial (danno esistenziale), como violação ao ser, buscando reparar posições constitucionalmente protegidas. A sentença 7.713/2000 envolveu um caso de abandono material de um filho. Nesse processo, o pai mesmo absolvido criminalmente, uma vez que o filho era sustentado pela mãe e pagou os valores alimentícios atrasados, foi condenado pela corte de Veneza, por ter se configurado dano existencial e à vida de relação. ${ }^{55}$

Desta forma, o dano existencial representa, em medida mais ou menos relevante, uma alteração substancial nas relações familiares, sociais, culturais ou afetivas. Pode acontecer em através de ação ou omissão que incide, negativamente, sobre o complexo de afazeres da pessoa, repercutindo de maneira consistente, temporária ou permanentemente, sobre a sua existência. ${ }^{56}$

Embora reconhecida sua aplicação no direito brasileiro pelos tribunais e, por conseguinte, no direito do trabalho com a reforma trabalhista, o dano existencial, como um dano imaterial, ganhou força a partir da Súmula 37 do Superior Tribunal de Justiça (STJ) e Súmula 491 do Supremo Tribunal Federal (STF), nos anos noventa, quando se reconhece a cumulação dos danos materiais e morais nos pedidos indenizatórios.

O dano existencial desprendido do dano moral, aparece em grande medida na seara trabalhista, fixando-se como extensão do dano à vida, ao projeto de vida da pessoa (do trabalhador). $\mathrm{O}$ dano moral encontra-se relacionado com o sentir, enquanto o dano existencial com um fazer (ou não poder fazer) ${ }^{57}$ Carlos Fernandes Sessarego $(2002$, p. 27) pon-

55 FALCÓN, 2015, p. 47-48.

56 FROTA, 2011.

57 MACCARONE, 2002, p. 77-78. 
tua o vazio existencial que o dano ao projeto de vida pode causar à pessoa:

El daño al proyecto de vida es un daño actual, que se proyecta al futuro. Es un daño cierto y continuado. Su más grave efecto es el de generar en el sujeto, que ve afectado en su totalidad su proyecto de vida, un vacío existencial por la pérdida de sentido que experimenta su vida. Son muchas y diversas las consecuencias de todo orden, [...], que surgen como consecuencia de este singular daño al proyecto de vida. La persona lesionada em cuanto al ejercicio de su libertad se sume en un explicable estado de desorientación, de depresión, de pérdida de seguridad y de confianza en sí misma, de ausencia de metas, de desconcierto. La angustiosa situación que envuelve a la víctima puede conducirla a la evasión a través de alguna adicción a las drogas o, en un caso límite, puede llevarla al suicidio. ${ }^{58}$ (SESSAREGO, 2002, p. 27)

Assim, o dano existencial, calcado na dignidade da pessoa humana, é um dano que se configura quando não se respeita o direito do trabalhador dosar a sua jornada laboral com o seu direito ao descanso. Enfim, configura-se com o desrespeito ao direito de gozar os seus momentos de folga. Guy Standing ${ }^{59}$ aponta que um aspecto preocupante da sociedade de trabalhadores regulares é a perda do respeito pelo ócio no sentido grego de schole, ócio como processo divertido, inspirador e prazeroso, mas também como opor-

58 Tradução livre: O dano ao projeto de vida é um dano atual, que é projetado no futuro. É um dano certo e contínuo. Seu efeito mais sério é o que causa no sujeito, que vê seu projeto de vida afetado em sua totalidade, causandolhe um vazio existencial e experimentando uma perda de significado em sua vida. As consequencias são muitas e de toda ordem, [...], surgem em conseqüência deste dano singular ao projeto de vida. A pessoa é ferida quanto ao exercício de sua liberdade, e se junta em um estado de desorientação, depressão, perda de segurança e autoconfiança, de ausência de metas, de confusão. A situação angustiada que envolve a vítima pode levar à fuga através de algum vício para drogas ou, em um caso extremado, pode levar ao suicídio. SESSAREGO, 2002, p. 27.

59 STANDING, 2017, 268. 
tunidade para o trabalhador refletir sobre sua participação cívica e democrática na sociedade. Defende-se que para a saúde da sociedade e para nós mesmos, precisamos de mecanismos para inverter essa tendência.

Jorge Cavalcanti Boucinhas Filho e Rúbia Zanotelli de Alvarenga ${ }^{60}$, ao versarem sobre o dano existencial no direito do trabalho, afirmam que este tem a ver com uma conduta do empregador capaz de impossibilitar o empregado de desenvolver suas relações sociais e familiares, capazes de lhes proporcionar prazer e bem-estar físico e psíquico, portanto, de experimentar momentos felizes. Afirmam que:

[...] Nos danos desse gênero o ofendido se vê privado do direito fundamental, constitucionalmente assegurado, de, respeitando o direito alheio, livre dispor de seu tempo fazendo ou deixando de fazer o que bem entender. Em última análise, ele se vê despojado de seu direito à liberdade e à sua dignidade humana [...] Portanto, é esse quadro oriundo da violação à existência do trabalhador, enquanto ser humano dotado de projetos de cunho pessoal, profissional e pessoal, que traz como consequência o comprometimento da sua saúde, que será responsável pelo aparecimento de doenças do trabalho que poderão colocar em risco a saúde física e mental do empregado. ${ }^{61}$

Desta feita, o meio ambiente do trabalho deve também levar em consideração a figura do trabalhador como alguém que possui planos e uma vida social e familiar que são fundamentais para sua saúde. Contexto mais amplo, diverso do mero não adoecimento, mas, principalmente, de como esse trabalhador vive no seu ambiente do trabalho, e do que pode fazer em seu tempo livre.

Saúde entrelaçada com a felicidade do trabalhador, sua paz e seu convívio no ambiente familiar, social, e até

60 BOUCINHAS FILHO; ALVARENGA, 2017, p. 2013.

61 BOUCINHAS FILHO; ALVARENGA, 2017, p. 2013. 
seu investimento educacional. Não há como dissociar esse direito do rol dos direitos fundamentais, caros ao trabalhador. Caracteriza-se como uma frustração dos objetivos de uma pessoa - no caso sob estudo, o trabalhador -, que se vê tolhido da possibilidade de concretizar sonhos e realizações em sua vida.

Rodrigo Castilho ${ }^{62}$ traz o conceito de dignidade da pessoa humana pautado na filosofia, indicando como suas fontes Giovanni Pico Della Mirandola ${ }^{63}$ e Immanuel Kant ${ }^{64}$. Feito isso, adentra na filosofia do Direito, segundo ele:

A dignidade humana é o princípio que humaniza o homem em suas relações sociais, que resgata o lado humano do homem, que lhe assegura a qualidade do ser e não de um ente ou objeto qualquer. É o princípio que impõe um tratamento humano ao homem. E o princípio que diferencia o homem das coisas e o vê como um fim em si mesmo. Resumindo: é o princípio que lhe possibilita ser existencialmente, decidir autônoma e racionalmente seus projetos de vida, e viver a vida do modo que se valoriza. ${ }^{65}$

A Constituição Federal de $1988^{66}$ reconhece a supremacia da dignidade da pessoa humana, valorando-a como um dos fundamentos da República Federativa do Brasil e pode-se verificar em várias passagens de seu texto a menção a esse princípio. $\mathrm{O}$ art. 170, trata da correlação entre a valorização do trabalho e a livre iniciativa como o fim de assegurar a todos existência digna.

Antônio Augusto Cançado Trindade ao tratar do indivíduo como titular de direitos aponta importantes considerações sobre o princípio da dignidade da pessoa humana

62 CASTILHO, 2013, p. 321-322.

63 MIRANDOLA, 2008.

64 KANT, 2011.

65 CASTILHO, 2013, p. 321-322.

66 BRASIL, 1988. 
como base para um conteúdo ético das normas internas e alienígenas:

Na base de todo esse notável desenvolvimento, encontra-se o princípio do respeito à dignidade da pessoa humana, independentemente de sua condição existencial. Em virtude desse princípio, todo ser humano, independentemente da situação e das circunstâncias em que se encontre, tem direito à dignidade. Todo o extraordinário desenvolvimento da doutrina jusinternacionalista a esse respeito, ao longo do século $\mathrm{XX}$, encontra raízes, - como não poderia deixar de ser, - em algumas reflexões do passado, no pensamento jurídico assim como filosófico, - a exemplo, inter alia, da concepção kantiana da pessoa humana como um fim em si mesmo. Isto é inevitável, porquanto reflete o processo de amadurecimento e refinamento do próprio espírito humano, que torna possíveis os avanços na própria condição humana. ${ }^{67}$

No entanto, a necessidade de dedicação ao trabalho e de manutenção do próprio sustento e o de seus familiares faz com que muitos trabalhadores se submetam às jornadas exaustivas, às escalas de folga que não coincidem com o dia de lazer da família e amigos. Quando o trabalhador permanece em constante sobreaviso, não há como descansar e desconectar das demandas laborais. Além disso, muitas vezes a jornada de trabalho impede ou dificulta a possibilidade de melhor qualificação. Essas condições põem em risco a dignidade e a própria existência do trabalhador, fragmentando a sua condição humana.

[..] quando falamos em "meio ambiente do trabalho", temos de olhar em sua volta - mas também por dentro dele. Temos de incluir não só o que está fora dos muros da empresa, mas o que se esconde por detrás da face visível do trabalho, atingindo o homem trabalhador. Em geral, os nossos olhos - por mais críticos que sejam - habituaram-se a enxergar apenas os salários precários, os acidentes do trabalho, os assédios morais ou sexuais, as jornadas exaustivas ou estressantes. [..] Esses problemas, é claro, são gra-

67 TRINDADE, 2012, p. 23-58. 
víssimos, mas acabam deixando nas sombras outras espécies de agressões, que na verdade nem mesmo são vistas como agressões. ${ }^{68}$

Há algo no ambiente de trabalho vivenciado pelos trabalhadores apto a desencadear pressões emocionais que influenciam na ocorrência desses infortúnios, em que pese toda a legislação existente que regula as normas que devem ser seguidas pelas empresas. Miguel Ferreira Filho ${ }^{69}$, em estudo sobre o ambiente do trabalho e o esgotamento do trabalhador também chamado Síndrome de Burnout, afirma que a origem desses males ocorre em decorrência de fatores estressantes e crônicos que ocorrem diariamente na atividade laboral.

O meio ambiente do trabalho deve ser saudável e respeitar os direitos humanos do trabalhador. O crescimento pelo crescimento, da forma como caminha o atual mercado, não pode seguir alheio à sustentabilidade e a necessária função socioambiental em que as empresas devem ter inclusive o meio ambiente do trabalho. A Organização Mundial da Saúde (OMS) conceitua meio ambiente do trabalho como sendo, in verbis:

aquele em que os trabalhadores e os gestores colaboram para o uso de um processo de melhoria contínua da proteção e promoção da segurança, saúde e bem-estar de todos os trabalhadores e para a sustentabilidade do ambiente de trabalho tendo em conta as seguintes considerações estabelecidas sobre as bases das necessidades previamente determinadas: - questões de segurança e saúde no ambiente físico de trabalho; - questões de segurança, saúde e bem-estar no ambiente psicossocial de trabalho, incluindo a organização do trabalho e cultura da organização; - recursos para a saúde pessoal no ambiente de trabalho; e envolvimento da empresa na comunidade para melhorar a saúde dos trabalhadores, de suas famílias e outros membros da comunidade. ${ }^{70}$

68 VIANA; TEODORO, 2017, p. 337.

69 FERREIRA FILHO, 2016.

70 OMS, 2010, p. 11. 
Um ambiente de trabalho que submete o trabalhador a longas jornadas e que não permite que este possa se desconectar, proporcionará um ambiente que o leva a exaustão, provoca um esvaziamento afetivo e um desgaste emocional, portanto apto a ser causador da síndrome relacionada ao esgotamento físico e mental do empregado. Entretanto, há outros fatores nem sempre considerados como a completa mercantilização de um homem pelo outro e, por vezes, por si mesmo. ${ }^{71}$

Sobre esse tema, André Molina ${ }^{72}$ diz que "Fala-se existencial porque o impacto gerado pelo dano provoca um vazio existencial na pessoa que perde a fonte de gratificação vital.". O dano existencial ocasiona uma lesão à relação e ao convívio que a pessoa precisa para se desenvolver pessoal, social e psicologicamente, afetando-o negativamente em suas escolhas de vida, merecendo o correspondente reparo.

A título de exemplo, julgado do Tribunal Superior do Trabalho considerou o labor em jornada exaustiva como dano existencial, sendo este uma espécie de dano imaterial apto a ser reparado pelo empregador:

RECURSO INTERPOSTO NA VIGÊNCIA DA LEI N ${ }^{\circ} 13.015 / 2014$. INDENIZAÇÃO POR DANO MORAL. JORNADA EXAUSTIVA. 15 (QUINZE) HORAS DIÁRIAS DE TRABALHO. DANO MORAL IN RE IPSA. PRESUNÇÃO HOMINIS. [...]. O Regional reconheceu "a jornada de trabalho excessiva do reclamante [...] como apta a configurar o dano moral existencial". [...]. Esta Corte tem entendido que a submissão habitual dos trabalhadores à jornada excessiva de labor ocasiona-lhes dano existencial, modalidade de dano imaterial e extrapatrimonial em que os empregados sofrem limitações em sua vida pessoal por força de conduta ilícita praticada pelo empregador, exatamente como na hipótese dos autos, importando em confisco irreversível de tempo que poderia

71 VIANA; TEODORO, 2017, p. 338.

72 MOLINA, 2015, p. 114. 
legitimamente destinar-se a descanso, convívio familiar, lazer, estudos, reciclagem profissional e tantas outras atividades, [...]. Recurso de revista não conhecido. ${ }^{73}$

Porém, esse reconhecimento não é pacífico e há decisões recentes que exigem a comprovação pelo trabalhador de qual projeto de vida foi afetado:

RECURSO DE REVISTA. DANO EXISTENCIAL. COMPENSAÇÃO. JORNADA DE TRABALHO EXAUSTIVA. NÃO CONFIGURAÇÃO. NÃO CONHECIMENTO. A jurisprudência deste Tribunal Superior vem se posicionando no sentido de que a sujeição do empregado à jornada extraordinária extenuante revela-se como causa de dano existencial, o qual consiste em uma espécie de dano imaterial. [...]. Na espécie, a egrégia Corte Regional, [...], registrou que para a configuração dessa espécie de dano é necessária comprovação do efetivo prejuízo ao convívio social e familiar do trabalhador [...]. Recurso de revista de que não se conhece. ${ }^{74}$

Essa desarmonia entre as decisões que analisam casos semelhantes fragiliza o reconhecimento e a necessidade de reparação do dano existencial. Em um julgado, considera-se o dano existencial presumido e no outro exige-se que haja real comprovação do dano. Ressalte-se que existe um intervalo de aproximadamente apenas um mês entre os acórdãos. Trata-se de um incentivo a perpetuação das condutas, ferindo-se a dignidade humana.

Além disso, é preciso tomar uma série de cuidados na fixação do valor da indenização. A vítima não deve suportar sozinha o dano existencial sofrido, leia-se o prejuízo à dignidade humana, por ato indevido de terceiro. $\mathrm{O}$ valor indenizatório para ser justo, deve para ser fixado, mergulhar na tarefa de restaurar o equilíbrio anteriormente existente. Deve tentar anular, desfazer ou atenuar os efeitos da danosidade. ${ }^{75}$

73 TST, 2017a.

74 TST, 2017b.

75 BONNA; LEAL, 2017, p. 69-70. 
Para tanto, a justiça corretiva, embora pareça tarefa relativamente simples, se revela desafiadora quando se está diante de danos existenciais, pois deve fixar valor indenizatório em proporção adequada para recompor ou compensar o dano na vida de uma pessoa específica, com uma história própria e projetos de vida peculiares, o que não condiz com a fixação padronizada de valor indenizatório, na medida em que o mesmo dano assume proporções díspares nos projetos de vida de cada um, não havendo um método cartesiano que possa averiguar o peso de bens imateriais na vida das vítimas. ${ }^{76}$

A prática judiciária mostra que há sempre a tendência para que a fixação do "quantum" indenizatório ocorra de forma automática e repetitiva, reafirmando-se o viés da modernidade relacionado à fragmentação da identidade, corolário da divisão de tarefas complexas. Interpreta-se a vida humana como eventos simples, isolados e episódicos, avaliando o valor da indenização compensatória tendo por base apenas os fatos necessários para caracterizar a responsabilidade. Evita-se a investigação de fatos que tornem a vida inteligível e possam fixar um valor justo suficiente para reestabelecer o equilíbrio na vida da vítima. ${ }^{77}$

A previsão expressa do dano existencial no direito do trabalho segue essa receita. $\mathrm{O}$ art. 223-B e seguintes da CLT, inseridos pela Lei 13.467, de 13 de junho de 2017, ao mesmo tempo que representaram um avanço, mostraram-se profundamente insensíveis à questão. É inaceitável, no caso do dano existencial, a aplicação de preceitos que levam o julgador a decisões que não ponderem profundamente acerca dos prejuízos ocasionados e dos meios para a sua reparação.

Além disso, a redação do art. 223-G, parágrafo $1^{\circ}$, da Consolidação das Leis do Trabalho (CLT) prevê, de maneira rígida, que uma vez julgado procedente o pedido o juízo fi-

76 BONNA; LEAL, 2017, p. 69-70.

77 BONNA; LEAL, 2017, p. 76. 
xará a indenização a ser paga, segundo parâmetros relativos à gravidade da ofensa. No caso de ofensa de natureza leve, está deve ser até três vezes o último salário recebido; no caso de ofensa de natureza média, até cinco vezes o último salário; quando reconhecido o dano de natureza grave, até vinte vezes o último salário e, por fim, no caso de ofensa de natureza gravíssima, a indenização será de até cinquenta vezes o último salário contratual.

A análise das dos julgados e da legislação brasileira ferem a dignidade do trabalhador, a ponto de o bem amoldar à personagem kafkiana. Trabalhadores que vivem o seu próprio trabalho e as suas necessidades, que quando se notam metamorfoseados em algo não humano, não se preocupam com a sua condição ou com a sua vida, mas com os seus trabalhos e a possibilidade de perdê-los.

Em outra de suas obras, Frans Kafka ${ }^{78}$ narra a vida de outro personagem que coloca o trabalho em um grau de importância acima de sua própria vida. O Artista da Fome - cujo ofício era jejuar -, viveu o seu trabalho a ponto de morrer. Não sabia outro ofício, não queria e nem podia ficar sem o seu trabalho. Afinal, o que iria ele fazer? Era velho demais para aprender outro ofício. Quando o interesse por seu jejum já não mais agradava o público, seguiu sem limites em sua arte (trabalho) até por fim a sua existência. $\mathrm{O}$ artista da fome que - tal como tantos trabalhadores - viveu e morreu para o seu trabalho. Foi muito além da máxima que prescreve que é necessário trabalhar para viver, distanciando-se do ensinamento bíblico.

“Navegar é preciso; viver não é preciso"79

78 KAFKA, 1998.

79 Expressão "navigare necesse; vivere non est necesse" é atribuída ao General romano Pompeu (106-48 a.C) que foi dita aos marinheiros, amedrontados, que se recusavam a viajar durante a guerra. 
Quero para mim o espírito [d] esta frase, transformada a forma para a casar como eu sou:

Viver não é necessário; o que é necessário é criar. Não conto gozar a minha vida; nem em gozá-la penso. Só quero torná-la grande, ainda que para isso tenha de ser o meu corpo e a (minha alma) a lenha desse fogo. ${ }^{80}$

O poeta Fernando Pessoa $^{81}$, ao refletir sobre a condição do homem e da sua vida no poema acima, avoca acima da sua própria existência a criação e a grandeza da vida e da humanidade. Aqui há uma grande diferença acerca da existência do homem. Investir a sua existência para algo maior é totalmente diferente de perder sua existência devido às exigências do trabalho. Navegar é preciso vai ao encontro de um viver criativo, prazeroso, a partir do pensamento de Russel, De Masi e tantos outros. Trata-se de um viver que não pode ser perdido no meio ambiente do trabalho explorador.

\section{CONCLUSÃO}

A interação dos homens com as máquinas não é novidade. No início, como agora, foram idealizadas para beneficiar o desenvolvimento do trabalho do homem. Entretanto, a análise da história do mundo do trabalho nos mostra que, ao mesmo tempo, o desenvolvimento das máquinas resultou na criação da esteira de produção das grandes fábricas. $\mathrm{O}$ ritmo do trabalho passou a ser frenético e ditado pela máquina. A figura do trabalhador posicionado na linha de produção, efetuando o seu trabalhado repetido, mecânico e específico inundou o imaginário das pessoas.

Duas características desta forma de trabalhar são marcantes, primeiro a de que a definição do ritmo do trabalho

80 PESSOA, 2018.

81 PESSOA, 2018. 
passou a ser ditada por um incansável agente externo, a esteira de produção. Além disso, a necessidade de divisão das atividades inundou a vida das pessoas. Problemas complexos passaram a ser divididos em subproblemas de mais fácil resolução. Essa maneira de pensar tornou-se cada vez mais comum e encontra-se presente no ideário da reparação de danos. O quantum indenizatório geralmente visa apenas ressarcir danos imediatos ou facilmente visíveis, sem que se tenha a preocupação no aprofundamento das questões mais complexas.

A partir do momento em que as máquinas de movimentos mecânicos passaram a ser substituídas pelos instrumentos eletrônicos surgiu uma nova esperança. Os mais sonhadores acreditavam que os seres humanos passariam a ter mais tempo para sua vida. O progresso das ferramentas faria com que os trabalhos repetitivos deixassem de existir e o trabalhador teria liberdade para cuidar do seu projeto de vida.

O mundo eletrônico, ao que parece, não cumpriu essa promessa, muito pelo contrário. Trouxe dois novos aspectos para o mundo do trabalho. O primeiro, a ideia, agora sempre presente, de que é mais fácil substituir do que consertar. Nos primórdios da eletrônica, quando um equipamento apresentava problemas ele era analisado por um técnico que, pacientemente, se dispunha a o corrigir. Esta prática está cada vez mais rara.

A velocidade exigida das soluções e a complexidade do mundo digital extirpou a figura desse técnico. Hoje, a qualquer problema, troca-se um grande conjunto de componentes inseparáveis, isso quando as exigências de custo e tempo não condenam todo o equipamento. Essa ideia também foi copiada para o mundo do trabalho, para o mundo das pessoas. Dificilmente investe-se muito na correção da 
atividade dos trabalhadores. É sempre mais fácil substituir o "componente" defeituoso por outro "perfeito".

Essa forma de pensar gera uma grande instabilidade no trabalhador, que fica a todo momento esperando a sua hora de ficar obsoleto ou apresentar defeito às vistas do seu contratante. Além do perigo da obsolescência, o trabalhador agora é acompanhado por diversas ferramentas de observação e controle que antes só existiam dentro das fábricas. O trabalhador pode ser contatado a qualquer momento. Torna-se cada vez menos comum a antiga ideia em que a atividade profissional está apartada da vida privada.

Aplicativos surgem a cada momento estabelecendo conexões constantes e intermináveis. Os mesmos instrumentos de comunicação que são utilizados pelo trabalhador, nos seus momentos de lazer, na sua vida privada, são compartilhados pelos seus contratantes. A cada chegada da mensagem no smartphone um sobressalto. $\mathrm{O}$ trabalhador não possui mais direito à desconexão, de dizer que não viu a mensagem, de adiar o atendimento. Tudo tem pressa, vive-se o just in time. Aquele que não se submente pode ser considerado defeituoso e pronto para troca.

É possível dizer que as últimas mudanças no mundo do trabalho não reservaram ao trabalhador posição vantajosa. Se no início da interação com a máquinas ele perdeu a possibilidade de impor o ritmo do trabalho, com a criação dos novos instrumentos eletrônicos escapou entre os seus dedos a possibilidade de definir confortavelmente quanto do seu tempo diário deverá estar reservado ao trabalho. Se não podia mais definir o seu ritmo de trabalho, agora não há mais fim de sua jornada laboral. O trabalhador, mesmo sem o sentir, metamorfoseou-se, falta-lhe apenas a devida consciência kafkiana. 
É nesse momento que adquire grande relevância a correta concepção do dano existencial. Visa-se mais coibir a prática da exploração do trabalhador do que obter o ressarcimento do prejuízo ocasionado ao seu projeto de vida. O dano existencial, desde a sua concepção, é um dano essencialmente de rara possibilidade de reparação. O tempo da vida de cada pessoa não retrocede, ele apenas marcha para a frente. Daí a importância da discussão mais apurada do problema, que certamente foi olvidada pelas alterações legislativas e decisões judiciais, elencadas nesse trabalho.

O dano existencial não visa reparar algo episódico, de fácil mensuração. Trata-se apenas de minorar os efeitos, muitas vezes, de anos de exploração, por vezes, inconsciente de que há um total ou parcial impedimento da execução do projeto de vida do trabalhador por parte de terceiro. $\mathrm{O}$ tabelamento do dano existencial, como foi incluído na lei trabalhista, bem como a necessidade de prova do efetivo prejuízo, demonstram que pouco se compreendeu, no mundo jurídico brasileiro, do que trata essa espécie de dano. Para melhor discernir, talvez seja necessário antes repetir, silenciosamente, parte do discurso de Chaplin" ${ }^{82}$, "Não sois máquina! Homens é que sois!".

\section{Referências bibliográficas}

ALMEIDA NETO. Amaro Alves de. Dano existencial: a tutela da dignidade da pessoa humana. Revista dos Tribunais. Revista de Direito Privado: RDPriv, v. 6, n. 24, p. 21-53, out./dez. 2005.Disponível em: http:/ / bdjur.stj.jus.br/dspace/handle/2011/87751. Acesso em: 28 abr. 2018.

ANTUNES, Ricardo. Adeus ao trabalho? Ensaio sobre as me-

82 CHAPLIN, 1940. 
tamorfoses e a centralidade do mundo do trabalho. 16. ed. São Paulo: Cortez, 2015.

ARENDT, Hanna. A condição humana. 11. ed. trad. Roberto Raposo. Rio de Janeiro: Forense, 2014.

BARROS, José D'Assunção. O conceito de alienação no jovem Marx. In: Tempo Social: revista de sociologia da USP, v. 23. n. 1, p. 223-245. jun. 2011, p. 229. Disponível em: <https:// www.revistas.usp.br/ts/article/viewFile/12659/14436>. Acesso em: 28 jan. 2018.

BAUMAN, Zygmunt. DONSKIS, Leonidas. Cegueira moral: a perda da sensibilidade na modernidade líquida. Trad. Carlos Alberto Medeiros. Rio de Janeiro: Zahar, 2014.

BAUMAN, Zygmunt. MAY, Tim. Aprendendo a pensar com a sociologia. Trad. Alexandre Werneck. Rio de Janeiro: Zahar, 2010.

BEBBER, Júlio César. Danos extrapatrimoniais (estético, biológico e existencial): breves considerações. Revista LTr, São Paulo, v. 73, n. 1, jan. 2009.

BEYNON, Huw. A destruição da classe operária inglesa? In: Revista Brasileira de Ciências Sociais. No. 27, Ano 10, fevereiro 1995. p.5-17. Disponível em: <http://www.anpocs.org.br/ portal/publicacoes/rbcs_00_27/rbcs27_01.htm>. Acesso em: 28 abr. 2018.

BLASS, Leila Maria da Silva. Trabalho e suas metamorfoses contemporâneas à luz do pensamento social clássico. In: Ponto e Vírgula, v. 1, p. 25-37, 2007. Disponível em: < https:/ / revistas.pucsp.br/index.php/pontoevirgula/article/download/14313/10462.>. Acesso em: 19 nov. 2017.

BONNA, Alexandre Pereira; LEAL; Pastora do Socorro Teixeira Leal. A responsabilidade civil como instrumento ético 
no plano interno e internacional de direitos humanos uma abordagem macintyriana. In: Revista Brasileira de Estudos Políticos. Belo Horizonte, n. 115, pp. 47-79, jul./dez. 2017.

BOUCINHAS FILHO, Jorge Cavalcanti; ALVARENGA, Rúbia Zanotelli de. O dano existencial e o direito do trabalho. In: Biblioteca Digital do Tribunal Superior do Trabalho. Disponível em: <http://aplicacao.tst.jus.br/dspace/bitstream/ handle/1939/39828 / 011_alvaren ga.pdf?sequence=1>. Acesso em: 20 out. 2017.

BRASIL, Poder Judiciário. Superior Tribunal de Justiça. Súmula 37. Disponível em: <http://www.stj.jus.br/docs_internet/VerbetesSTJ_asc.pdf>. Acesso em: 20 mar. 2018.

BRASIL, Poder Judiciário. Supremo Tribunal Federal. Súmula 491. Disponível em: <http://portal.stf.jus.br/textos/ verTexto.asp?servico=jurisprudenciaSumula\&pagina=sum ula_401_500>. Acesso em: 20 mar. 2018.

Tribunal Superior do Trabalho (TST). Recurso de Revista: TST-RR-402-61.2014.5.15.0030 (4026120145150030). $2^{\text {a }}$ Turma. Recorrente: Tropical Transportes Ipiranga Ltda. Recorrido: Alcidnei Gomes. Relator: Ministro José Roberto Freire Pimenta. Brasília, 08 de novembro de 2017. Disponível em: <https:/ / tst.jusbrasil.com.br/jurisprudencia/519735775/ recurso-de-revista-rr-4026120145150030/inteiro-teor-519735796?ref=juris-tabs>. Acesso em: 26 nov. 2017.

Tribunal Superior do Trabalho (TST). Recurso de Revista: TSTRR-1463-18.2015.5.06.0144 (14631820155060144). $5^{\mathrm{a}}$ Turma. Recorrente: Romero Luiz da Silva. Recorrido: Norsa Refrigerantes Ltda. Relator: Ministro Guilherme Augusto Caputo Bastos. Brasília, 11 de outubro de 2017. Disponível em: <https://tst.jusbrasil.com.br/ jurisprudencia/514467737/ recurso-de-revista-rr-14631820155060144?ref=juris-tabs>. Acesso em: 26 nov. 2017. 
BRASIL. Poder Executivo. Decreto-lei no 5.452, de $1^{\circ}$ de maio de 1943. Aprova a Consolidação das Leis do Trabalho. Disponível em: http://www.planalto.gov.br/ccivil_03 / decreto-lei/Del5452.htm. Acesso em: 09 jun. 2018.

BRASIL. Poder Legislativo. Constituição (1988). Disponível em: <http://www.planalto.gov.br/ccivil_03/constituicao/ constituicaocompilado.htm>. Acesso em: 25 nov. 2017.

BRASIL. Poder Legislativo. Lei 13.647, de 13 de julho de 2017. Altera a Consolidação das Leis do Trabalho. Disponível em: http:/ / www.planalto.gov.br/ccivil_03/_ato20152018/2017/lei/113467.htm. Acesso em: 09 jun. 2018.

CASTELLS, Manuel. A Sociedade em rede. Tad. Roneide Venancio Majer. 17 a ed. São Paulo: Paz e Terra, 2016.

CASTILHO, Rodrigo. "As restrições de fato ou materiais aos direitos fundamentais como violação do dever de proteção adequada e suficiente do estado: prestações exigíveis do estado para a tutela de direitos sociais do trabalhador". In: MIESSA, Élisson; CORREIA, Henrique (Org.). Estudos aprofundados MPT: ministério público do trabalho. 2. ed. Salvador: JusPODIVM, 2013.

CHAPLIN, Charles. Tempos Modernos. Titulo Original: Modern Times. Preto \& Branco. Legendado. Duração: $87 \mathrm{~min}$. Warner, 1936.

CHAPLIN, Charles. O Grande Ditador. Titulo Original: The Great Dictator. Preto \& Branco. Legendado. Duração: 87 min. Warner, 1940.

COUTO E SILVA, Clovis Veríssimo do. O conceito de dano no direito brasileiro e comparado In: Fradera, Vera Maria Jacob de (org.). O Direito Privado Brasileiro Na Visão de Clóvis do Couto e Silva. Porto Alegre: Livraria do Advogado, 1997. p. 217-234. 
DEJOURS, Christophe. A loucura do trabalho: estudo de psicopatologia do trabalho. Trad. Ana Isabel Paraguay e Lúcia Leal Ferreira. 5a ed. São Paulo: Corteza Editora, 1987.

DELEUZE, Gilles. "Pensamento nômade.", In: Marton, Scarlett (org). Nietzsche hoje?. São Paulo: Brasiliense, 1985.

FALCÓN, Candelaria Aráoz. Dano ao "Projeto de Vida": Um Novo Horizonte às Reparações Dentro do Sistema Interamericano de Direitos Humanos? In: Revista Direitos Humanos e Democracia. Unijuí. ano. 3. n. 5. jan./jun. 2015. ISSN 2317-5389. p. 47-88. Disponível em: <https:/ /www.revistas. unijui.edu.br/index.php/direitoshumanosedemocracia/ article/download/4039/4679>. Acesso em: 20 nov. 2017.

FERREIRA FILHO, Miguel. O meio ambiente laboral e a síndrome de burnout como acidente de trabalho: breves reflexões. In. GUNHTER, Luiz Eduardo. ALVARANGA, Rúbia Zanotelli de. (Coord.). BUSNARDO, Juliana Cristina. BACELLAR, Regina Maria Bueno. (Org.). Direitos humanos e meio ambiente do trabalho. São Paulo: LTr, 2016.

FROTA, Hidemberg Alves da. Noções fundamentais sobre o dano existencial. Revista Jus Navigandi, ISSN 1518-4862, Teresina, ano 16, n. 3046, 3 nov. 2011. Disponível em: <https:/ / jus.com.br/artigos/20349>. Acesso em: 9 jun. 2018.

HAN, Byung-Chul. Psicopolitica: neoliberalismo e novas técnicas de poder. Trad. Miguel Serras Pereira. São Paulo: Relógio d'Água Editores, 2015.

HOLlANDA, Chico Buarque. Pedro Pedreiro. 1966. Disponível em: https://www.vagalume.com.br/chico-buarque/ pedro-pedreiro.html. Acesso em 27 abr. 2018.

KAFKA, Franz. A Metamorfose. KAFKA, Franz. A Metamorfose. Trad. Modesto Carone. São Paulo: Companhia das Letras, 1997. 
KAFKA, Franz. Um artista da fome e a construção. Trad. Modesto Carone. São Paulo: Companhia das Letras, 1998.

KANT, Immanuel. Fundamentação da metafísica dos costumes. Tradução de: Paulo Quintela. Lisboa: Edições 70, 2011.

LANDES, David S. The Unbound Prometheus. New York: Cambridge Press, 1988.

MACCARONE, M. Le imissione. Tutela reale e tutela della persona. Milano: Giuffrè, 2002.

MARCHESINI JUNIOR, Atilio. O modelo de vida alienante da "sociedade do consumo". In: Ateliê Geográfico. v. 6. n. 2, p. 131-147, ago/2012. Disponível em: <https:/ / revistas.ufg. br/atelie/article/download/16270/11458>. Acesso em: 05 mar. 2018.

MARX, Karl. Manuscritos econômicos-filosóficos. Trad. Jesus Ranieri. São Paulo: Boitempo, 2008, p. 80-81.

MASI, Domenico De. O ócio criativo: entrevista a Maria Serena Palieri. Trad. Léa Manzi. Rio de Janeiro: Sextante, 2000.

MÉSZÁROS, Istvan. A montanha que devemos conquistar: reflexões acerca do Estado. E-book. Trad. Maria Izabel Lagoa. São Paulo: Boitempo, 2015.

MIRANDOLA, Giovanni Pico Della. Discurso sobre a dignidade do homem. Tradução de: Maria de Lurdes Sirgado Ganho. Lisboa: Edições 70, 2008

MOLINA, André Araújo. Dano existencial por jornada de trabalho excessiva: critérios objetivos (horizontais e verticais) de configuração. In: Revista do Tribunal Superior do Trabalho, São Paulo, SP, v. 81, n. 4, p. 107-134, out./dez. 2015. Disponível em: <https://juslaboris.tst.jus.br/handle/1939/93093>. Acesso em: 25 nov. 2017. 
NATIONAL GEOGRAPHIC SOCIETY (NGS). Drugs, Inc. Disponível em: <http://channel.nationalgeographic.com/ drugs-inc/>. Acesso em: 26 abr. 2018.

ORGANIZAÇAO MUNDIAL DA SAÚDE. Ambientes de trabalho saudáveis: um modelo para ação: para empregadores, trabalhadores, formuladores de política e profissionais. Brasília: SESI/DN, 2010.

PESSOA, Fernando. Navegar é preciso. Blog Textos para Reflexão. Disponível em: <http://textosparareflexao.blogspot.com/2010/05/navegar-e-preciso.html>. Acesso em: 24 mar. 2018.

ROCHA, Cláudio Jannotti da. O homem, o trabalho e a sociedade: uma relação de completude. In: ROCHA, Cláudio Jannotti da; PORTO, Lorena Vasconcelos (Org.). Trabalho: diálogos e críticas: homenagem ao Prof. Dr. Márcio Túlio Viana. v. 1. São Paulo: LTr, 2018.

RUSSELL, Bertrand. Elogio ao ócio. 2. ed. Trad. Pedro Jorgensen Júnior. Rio de Janeiro: Sextante, 2002.

SEN, Amartya. Desenvolvimento como liberdade. São Paulo: Companhia das Letras, 2010.

SESSAREGO, Carlos Fernández. Apuntes sobre el daño a la persona. Diké. Portal de Información y Opinión Legal: Pontificia Universidad Católica del Perú, 2002, p. 27. Disponível em: <http://dike.pucp.edu.pe/bibliotecadeautor_carlos_fernandez_cesareo/articulos/ba_fs_4. PDF>. Acesso em: 24 mar. 2018.

STANDING, Guy. O precariado: a nova classe perigosa. Trad. Cristina Antunes. Belo Horizonte: Autêntica Editora, 2017. TRINDADE, Antônio Augusto Cançado. “Os indivíduos como sujeitos do direito internacional". In: TRINDADE, 
Antônio Augusto Cançado; LEAL, César Oliveira de Barros (Org.). In: Revista do Instituto Brasileiro de Direitos Humanos. Fortaleza, v. 12, n. 12, p. 23-58, 2012.

UNIVERSITÁ DI TRENTO (UT). Il Codice Civile. Libro Quatro: Delle Obbligazioni. Disponível em: <http://www. jus.unitn.it/cardozo/obiter_dictum /codciv/Lib4.htm>. Acesso em: 20 mar. 2018.

VIANA, Márcio Túlio; TEODORO, Maria Cecília Máximo. Misturas e fraturas do trabalho: do poder diretivo à concepção do trabalho como necessidade. In: Revista Brasileira de Estudos Políticos, Belo Horizonte, n. 114, p. 299-343, jan./ jun. 2017

Recebido em 28/06/2018.

Aprovado em 03/10/2018.

\section{Alexandre Antonio Bruno da Silva}

E-mail:alexandre_bruno@terra.com.br

Marlea Nobre da Costa Maciel

E-mail:marleanobre@hotmail.com 
